\title{
A study on structural stability of bismuth titanate with lanthanum doping for improved ferroelectric properties
}

\author{
UMAR AL-AMANI AZLAN ${ }^{1, *}$ and AHMAD FAUZI MOHD NOOR ${ }^{2}$ \\ ${ }^{1}$ Faculty of Engineering Technology, Universiti Teknikal Malaysia Melaka, 76100 Durian Tunggal, Malaysia \\ ${ }^{2}$ School of Material and Mineral Resources Engineering, Engineering Campus, Universiti Sains Malaysia, 14300 Nibong \\ Tebal, Malaysia \\ *Author for correspondence (umar@utem.edu.my)
}

MS received 29 February 2016; accepted 13 July 2016; published online 13 May 2017

\begin{abstract}
Bismuth titanate $\left(\mathrm{Bi}_{4} \mathrm{Ti}_{3} \mathrm{O}_{12}\right)$ with different lanthanum $(\mathrm{La})$ concentrations $(0.25,0.50,0.75$ and 1.0 mol\%) was successfully prepared via soft combustion route. It was found that the change of diffraction peaks shown by X-ray diffraction is attributed to the doping effect in $\mathrm{Bi}_{4} \mathrm{Ti}_{3} \mathrm{O}_{12}$. This was also supported by the presence of additional peak that corresponds to $\mathrm{La}$ in the range of $800-860 \mathrm{eV}$, proved by X-ray photoelectron spectroscopy. In addition, the enlarged region of $\mathrm{Bi} 4 \mathrm{f}$, $\mathrm{Bi}$ 4d, Ti 2p, La 3d and O 1s of doping sample was clearly seen after deconvolution. Based on binding energy position, it can be unambiguously stated that the $\mathrm{Ti}$ ions in the tetravalent state are surrounded by the perovskite layer of $\mathrm{Bi}_{4} \mathrm{Ti}_{3} \mathrm{O}_{12}$, which may also imply the formation of oxygen vacancies in the vicinity of the $\mathrm{Bi}_{2} \mathrm{O}_{2}$ layer. In comparison with $\mathrm{Bi}_{4} \mathrm{Ti}_{3} \mathrm{O}_{12}$, the green emission intensity was abruptly decreased with La doping. This indicates that La doping suppresses the formation of oxygen vacancies by stabilizing the adjacent oxide ions. Thus, the improved polarization shown by ferroelectric hysteresis loop is associated with the reduction in oxygen and bismuth vacancies due to La doping.
\end{abstract}

Keywords. $\mathrm{Bi}_{4} \mathrm{Ti}_{3} \mathrm{O}_{12}$; lanthanum; oxygen vacancies; ferroelectric.

\section{Introduction}

Lead-free ceramics have been widely used as ferroelectric materials as they are environment friendly and less toxic. Among these ceramics, bismuth titanate, $\mathrm{Bi}_{4} \mathrm{Ti}_{3} \mathrm{O}_{12}$ (BIT), has received special attention due to its potential for the development of memory technologies such as dynamic random access memory (DRAM) and ferroelectric random access memories (FRAM) [1]. In general, BIT is a member of Aurivillius compound with a high Curie temperature $\left(T_{\mathrm{c}}=675^{\circ} \mathrm{C}\right)$, high dielectric constant $\left(\varepsilon_{\mathrm{r}}=100-200\right)$, low dielectric loss $(\tan \delta=0.005-0.05)$, high remanent polarization $\left(P_{\mathrm{r}}=5-7 \mu \mathrm{C} \mathrm{cm}^{-2}\right)$ and low coercive field $\left(E_{\mathrm{c}}=20-50 \mathrm{kV} \mathrm{cm}^{-1}\right)[2,3]$. However, several shortcomings of $\mathrm{Bi}_{4} \mathrm{Ti}_{3} \mathrm{O}_{12}$ limit its capability for more advanced applications.

It was reported that $\mathrm{Bi}$ ions, located at $\mathrm{A}$-site in $\mathrm{ABO}_{3}$ of $\mathrm{Bi}_{4} \mathrm{Ti}_{3} \mathrm{O}_{12}$ structure, are known to be unstable due to easy volatility during sintering at temperature above $1000^{\circ} \mathrm{C}$ [4]. It was also stated that the oxygen near the $\mathrm{Bi}$ ions is likely to be less stable due to the volatility of the Bi ions [1]. Thus, defects, such as bismuth vacancies ( $\left.\mathrm{VBi}^{\prime \prime \prime}\right)$ and oxygen vacancies (Vo*), could exist in the perovskite layers and act as a space charge. The presence of space charge implies that $\mathrm{Bi}_{4} \mathrm{Ti}_{3} \mathrm{O}_{12}$ has critical drawbacks in its ferroelectric properties such as high leakage current and domain pinning, which leads to small remanent polarization and low fatigue endurance.
In general, improved properties of $\mathrm{Bi}_{4} \mathrm{Ti}_{3} \mathrm{O}_{12}$ can be achieved by rare-earth doping. The doping by rare earths is a feasible method to improve the stability structure of $\mathrm{Bi}_{4} \mathrm{Ti}_{3} \mathrm{O}_{12}$ which then results in better ferroelectric properties. In addition, the doping for $\mathrm{Bi}$ in $\mathrm{Bi}_{4} \mathrm{Ti}_{3} \mathrm{O}_{12}$ structure is more appropriate by rare-earth that acquire similar ion valences such as lanthanum (La), cerium (Ce), praseodymium ( $\mathrm{Pr})$, neodymium $(\mathrm{Nd})$ and samarium $(\mathrm{Sm})$. In principle, the role of doping is to relocate the volatile $\mathrm{Bi}$ ions with rare earths which in turn suppress the Bi vacancies accompanied by oxygen vacancies [5]. In other words, the space charge effect can be minimized and subsequently result in large remanent polarization and good fatigue endurance after switching cycles.

There have been several reports on the structure and properties of rare-earth-doped $\mathrm{Bi}_{4} \mathrm{Ti}_{3} \mathrm{O}_{12}$ ceramics. Mao et al [6] claimed that maximum remanent polarization was reached with a certain $\mathrm{Nd}$ doping, whereby the improved ferroelectric properties are associated with the decrease of the oxygen vacancy concentration and the increase of mobility of domain wall [6]. Meanwhile, Kim et al [5] found that $\mathrm{Nd}$ doping leads to small grain size, high dielectric constant, low dissipation factor, large remanent polarization and low conductivity [5]. Chen et al [7] reported that the maximum remanent polarization of about $16 \mu \mathrm{C} \mathrm{cm}^{-2}$ and minimum coercive field of about $70 \mathrm{kV} \mathrm{cm}^{-1}$ was obtained for $\mathrm{Sm}=0.8$ [7]. In another report by Noguchi et al [8], they concluded that that La doping was found to be an effective way 
to reduce the oxygen vacancies and electron holes [8]. Based on these reports, there is little work to clearly demonstrate the reduction of oxygen vacancies as a result of rare-earth doping. In this work, the evidence to show the minimum presence of oxygen vacancies in La-doped samples is discussed.

\section{Experimental}

Bismuth nitrate pentahydrate $\left(\mathrm{Bi}\left(\mathrm{NO}_{3}\right)_{3} \cdot 5 \mathrm{H}_{2} \mathrm{O}\right)$ and 0.25 , $0.50,0.75$ and $1.00 \mathrm{~mol} \%$ lanthanum nitrate hexahydrate $\left(\mathrm{La}\left(\mathrm{NO}_{3}\right)_{3} \cdot 6 \mathrm{H}_{2} \mathrm{O}\right)$ were dissolved in distilled water for $2 \mathrm{~h}$ with constant stirring at $40^{\circ} \mathrm{C}$. Separately, Ti(IV) isopropoxide $\left(\mathrm{Ti}\left(\mathrm{OCH}\left(\mathrm{CH}_{3}\right)_{2}\right)_{4}\right)$ was dissolved in 2-methoxyethanol for $30 \mathrm{~min}$ with constant stirring at room temperature, $25^{\circ} \mathrm{C}$. Aqueous solution of citric acid was prepared to be used as fuel agent and chelating agent. After that, the Ti solution was poured into the Bi solution using a dropping funnel, and subsequently the aqueous citric acid was added. The use of dropping funnel is necessary to obtain a good precursor with better homogeneity. Ammonium hydroxide, $\mathrm{NH}_{4} \mathrm{OH}(29 \%$ solution), was then added dropwise to achieve $\mathrm{pH}$ 7. The obtained precursor was constantly stirred for another $24 \mathrm{~h}$ at $60^{\circ} \mathrm{C}$. During this stage, a milky solution was formed. The temperature was increased to $80^{\circ} \mathrm{C}$ to form a wet paste-like white precipitates. The precipitated paste was subsequently dried in an oven at $80^{\circ} \mathrm{C}$ overnight. This practice is highly recommended in this work to obtain dried powder with more uniform colour. The dried powder was heated on a hot plate to combust into powder. The temperature was determined using a thermocouple (K-type, maximum detection at $1200^{\circ} \mathrm{C}$ ). The combustion reaction lasted for less than 2 min to produce a yellowish powder. The as-combusted powder was softly crushed using an agate mortar and a pestle and pressed into pellet form with $13 \mathrm{~mm}$ diameter. The prepared pellet was sintered at $1000^{\circ} \mathrm{C}$ for $3 \mathrm{~h}$ in an electrical furnace. Table 1 shows the formula of samples with respective La concentration.

Characterizations and ferroelectric measurement on produced samples were performed. Phase formation of the as-combusted powders was analysed by X-ray diffraction (XRD, Bruker D8-Discovery, Germany). The valence states of constituent elements and binding energies were determined by X-ray photoelectron spectroscopy (XPS, Ultra Axis PLD, Kratos). In addition, a conclusion about the possible position

Table 1. Formula of samples with respective La concentration.

\begin{tabular}{lc}
\hline Sample & La concentration (mol\%) \\
\hline $\mathrm{Bi}_{4} \mathrm{Ti}_{3} \mathrm{O}_{12}$ & 0.00 \\
$\mathrm{Bi}_{3.75} \mathrm{La}_{0.25} \mathrm{Ti}_{3} \mathrm{O}_{12}$ & 0.25 \\
$\mathrm{Bi}_{3.50} \mathrm{La}_{0.50} \mathrm{Ti}_{3} \mathrm{O}_{12}$ & 0.50 \\
$\mathrm{Bi}_{3.25} \mathrm{La}_{0.75} \mathrm{Ti}_{3} \mathrm{O}_{12}$ & 0.75 \\
$\mathrm{Bi}_{3.00} \mathrm{La}_{1.00} \mathrm{Ti}_{3} \mathrm{O}_{12}$ & 1.00 \\
\hline
\end{tabular}

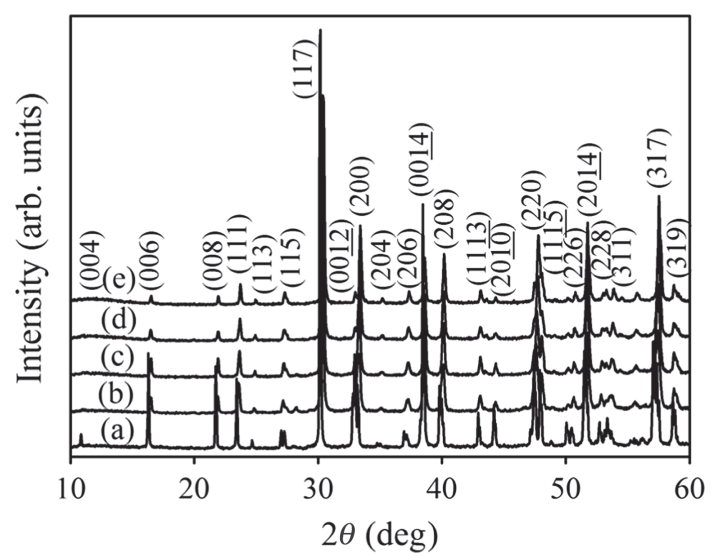

Figure 1. $\mathrm{XRD}$ patterns of $\mathrm{Bi}_{4} \mathrm{Ti}_{3} \mathrm{O}_{12}$ and $\mathrm{La}$ doping samples sintered at $1000^{\circ} \mathrm{C}$ for $3 \mathrm{~h}$ : (a) $\mathrm{Bi}_{4} \mathrm{Ti}_{3} \mathrm{O}_{12}$, (b) $\mathrm{Bi}_{3.75} \mathrm{La}_{0.25} \mathrm{Ti}_{3} \mathrm{O}_{12}$, (c) $\mathrm{Bi}_{3.50} \mathrm{La}_{0.50} \mathrm{Ti}_{3} \mathrm{O}_{12}$, (d) $\mathrm{Bi}_{3.25} \mathrm{La}_{0.75} \mathrm{Ti}_{3} \mathrm{O}_{12}$ and (e) $\mathrm{Bi}_{3.00} \mathrm{La}_{1.00} \mathrm{Ti}_{3} \mathrm{O}_{12}$

of the oxygen vacancies could be also derived. The intrinsic defects formed in the BIT lattice were characterized through photoluminescence (PL) test (Horiba Jobin Yvon Spectrometer). Polarization-electrical field $(P-E)$ hysteresis loops were measured using a Sawyer Tower circuit at room temperature.

\section{Results and discussion}

\subsection{XRD analysis}

The XRD patterns of $\mathrm{Bi}_{4} \mathrm{Ti}_{3} \mathrm{O}_{12}$ with different La concentrations prepared by combustion synthesis and subsequently sintered at $1000^{\circ} \mathrm{C}$ are illustrated in figure 1 . The diffraction peaks were analysed and indexed according to the perovskite structure of $\mathrm{Bi}_{4} \mathrm{Ti}_{3} \mathrm{O}_{12}$. It clearly indicates that the observed patterns are similar to the $\mathrm{Bi}_{4} \mathrm{Ti}_{3} \mathrm{O}_{12}$ perovskite structure, predominantly with (117)-axis orientation. In addition, the doped samples do not show any evidence of the formation of secondary phase. This indicates that the $\mathrm{La}$ ions in the $\mathrm{Bi}_{4} \mathrm{Ti}_{3} \mathrm{O}_{12}$ are well dissolved into the perovskite lattice. The peak intensity and position are obviously different for doped samples as compared with $\mathrm{Bi}_{4} \mathrm{Ti}_{3} \mathrm{O}_{12}$. As seen in figure 1, the (117)reflection intensity of doped samples was reduced and the peak position was shifted to higher angles with increasing La concentration. The reduction of peak intensity is due to low crystallinity of doped samples. The shift in peak position indicates the structural distortion, owing to the doping of $\mathrm{La}$ for $\mathrm{Bi}$ ions in perovskite structure.

\subsection{XPS analysis}

XPS analysis was conducted to identify the chemical composition and oxidation state of $\mathrm{Bi}_{4} \mathrm{Ti}_{3} \mathrm{O}_{12}$ and La-doped samples. The XPS spectra of $\mathrm{Bi}_{4} \mathrm{Ti}_{3} \mathrm{O}_{12}$ and $\mathrm{Bi}_{3.00} \mathrm{La}_{1.00} \mathrm{Ti}_{3} \mathrm{O}_{12}$ are presented in figure $2 \mathrm{a}$ and $\mathrm{b}$, respectively. Both figures were 

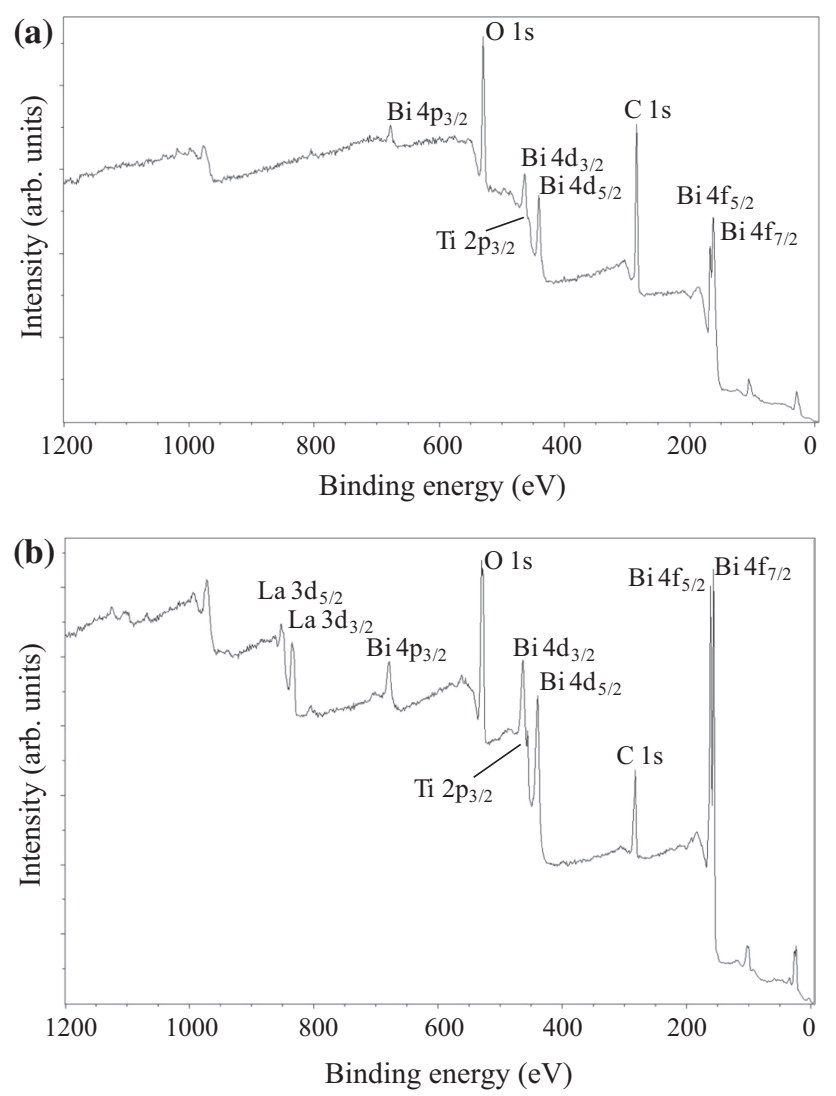

Figure 2. XPS spectra of (a) $\mathrm{Bi}_{4} \mathrm{Ti}_{3} \mathrm{O}_{12}$ and (b)

$\mathrm{Bi}_{3.00} \mathrm{La}_{1.00} \mathrm{Ti}_{3} \mathrm{O}_{12}$.

indexed by several oxidation states of the elements with different binding energies from 0 to $1200 \mathrm{eV}$. In order to analyse the XPS data, all the binding energies at various peaks were calibrated using the binding energy of C $1 \mathrm{~s}(284.6 \mathrm{eV})$. However, the $\mathrm{C} 1 \mathrm{~s}$ photoelectron peak was observed at 285 and 283 $\mathrm{eV}$ in BIT and BLaT100, respectively, instead of $284.6 \mathrm{eV}$. The difference in binding energy of $\mathrm{C} 1 \mathrm{~s}$ is due to the charge of dielectric specimens during analysis [9]. As seen in figure $2 \mathrm{a}$, the photoemission of $\mathrm{Bi} 4 \mathrm{f}, \mathrm{Bi} 4 \mathrm{~d}$, Ti $2 \mathrm{p}$ and $\mathrm{O} 1$ s core levels is sensitive to the oxidation states of the element constituting the $\mathrm{Bi}_{4} \mathrm{Ti}_{3} \mathrm{O}_{12}$ compound. In comparison with doped samples (figure $2 \mathrm{~b}$ ), an additional peak that corresponds to $\mathrm{La}$ was obviously detected in the range of $800-860 \mathrm{eV}$, proving the incorporation of $\mathrm{La}$ in $\mathrm{Bi}_{4} \mathrm{Ti}_{3} \mathrm{O}_{12}$.

Figure 3 shows the enlarged region of Bi 4f, Bi 4d, Ti 2p, La $3 \mathrm{~d}$ and $\mathrm{O} 1 \mathrm{~s}$ of BLaT100 samples. The deconvolution was performed through the PeakFit program (version 4.12). In figure $3 \mathrm{a}$, the $\mathrm{Bi} 4 \mathrm{f}$ region is divided into two different oxidation states of $\mathrm{Bi}$. The $\mathrm{Bi} 4 \mathrm{f}_{5 / 2}$ and $\mathrm{Bi}_{4} \mathrm{f}_{7 / 2}$ are located, respectively, at 162.1 and $156.7 \mathrm{eV}$. This implies that the typical value of binding energy for $\mathrm{Bi} 4 \mathrm{f}$ is $5.4 \mathrm{eV}$, which is almost close to the reported value in another work $(5.3 \mathrm{eV})$ [10]. The core level XPS spectra of Bi $4 \mathrm{~d}$ and Ti 2p of BLaT100 are shown in figure $3 \mathrm{~b}$. It can be seen that the $\mathrm{Ti} 2 \mathrm{p}_{3 / 2}$ photoemission peak is a distinctively resolved feature located at $455.4 \mathrm{eV}$.
The binding energy of Ti $2 \mathrm{p}$ is nearly close to the $\mathrm{PbTiO}_{3}$ of about $457.9 \mathrm{eV}$ [10]. Based on its binding energy position, it can be unambiguously concluded that the Ti ions in the tetravalent state are surrounded by the perovskite layer of $\mathrm{Bi}_{4} \mathrm{Ti}_{3} \mathrm{O}_{12}$. This also implies the formation of oxygen vacancies in the vicinity of the $\mathrm{Bi}_{2} \mathrm{O}_{2}$ layer, which is in agreement with the previous report [9].

Figure $3 \mathrm{c}$ exhibits the photoemission spectrum of La 3d core level peak. It can be seen that the binding energies of $\mathrm{La}$ $3 \mathrm{~d}_{5 / 2}$ and $\mathrm{La} 3 \mathrm{~d}_{3 / 2}$ levels are 832.3 and $849.4 \mathrm{eV}$, respectively. The energy difference between the $\mathrm{La} 3 \mathrm{~d}_{3 / 2}$ and $\mathrm{La} 3 \mathrm{~d}_{5 / 2}$ states is approximately $17 \mathrm{eV}$, which is in agreement with the character value of $\mathrm{La}_{2} \mathrm{O}_{3}[11,12]$. In addition, the presence of $\mathrm{La}^{3+}$ in $\mathrm{Bi}_{4} \mathrm{Ti}_{3} \mathrm{O}_{12}$ is confirmed. A distinct satellite peak associated with $\mathrm{La} 3 \mathrm{~d}_{5 / 2}$ peak is observed at the higher binding energy of $836.2 \mathrm{eV}$. Another satellite peak for La $3 \mathrm{~d}_{3 / 2}$ appears at $853.2 \mathrm{eV}$. The formation of the satellite peaks is associated with the electron deficiency in core hole in the La 3d. Similar satellite peaks were observed for $\mathrm{Cu} 2 \mathrm{p}$ [13]. The formation of satellite peaks corresponds to $2 \mathrm{p}^{2} \mathrm{~d}^{9}$ configuration, whereby there is one electron missing (core hole) in the $\mathrm{Cu} 2 \mathrm{p}$. In a photoelectron emission process, electron charges are transferred from the surrounding to the core holes. Therefore, this situation causes the main peak to be associated with a satellite at higher binding energy. This also implies that $\mathrm{La} 3 \mathrm{~d}$ is formed by the main and satellite peaks. The existing satellites confirm the existence of $\mathrm{La}^{3+}$. The presence of $\mathrm{La}^{3+}$ also supports the fact that $\mathrm{La}-\mathrm{O}$ bond is stable in the crystal structure. The $\mathrm{O} 1 \mathrm{~s}$ spectrum shown in figure $3 \mathrm{~d}$ can be divided into two spin-orbit doublet components at 527.4 and $529.9 \mathrm{eV}$. It was reported that the oxygen atom in a stronger Ti-O bond carries a higher effective negative charge than in a weaker $\mathrm{Bi}-\mathrm{O}$ bond [10]. In figure $3 \mathrm{~d}$, the first one at lower binding energy side corresponds to the stronger Ti-O bonds while the second peak is ascribed to $\mathrm{Bi}-\mathrm{O}$ bonds.

\subsection{PL analysis}

The PL spectra of $\mathrm{Bi}_{4} \mathrm{Ti}_{3} \mathrm{O}_{12}$ and doped samples excited at $325 \mathrm{~nm}$ and room temperature are shown in figure 4. In general, the PL profiles of $\mathrm{Bi}_{4} \mathrm{Ti}_{3} \mathrm{O}_{12}$ demonstrate an emission mechanism that is contributed by different types of electronic transition within the band gap. The origin of this PL emission can be associated with the contribution of different light emission components. Therefore, in order to estimate the contribution of each individual component, it was necessary to deconvolute the PL spectra of $\mathrm{Bi}_{4} \mathrm{Ti}_{3} \mathrm{O}_{12}$ and La-doped samples and the results are shown in figure 4 . The deconvolution was performed through the PeakFit program (version 4.12) following the rule of Gaussian fit. As seen, the deconvolution results showed the presence of numerous visible light emissions. The PL spectrum of BIT was adjusted by three emissions, i.e., violet, green and orange (figure 4a). The first peak located at $376 \mathrm{~nm}$ is responsible for the violet emission. The second peak situated at $518 \mathrm{~nm}$ corresponds to the green light emission. The third peak located at $605 \mathrm{~nm}$ is ascribed 

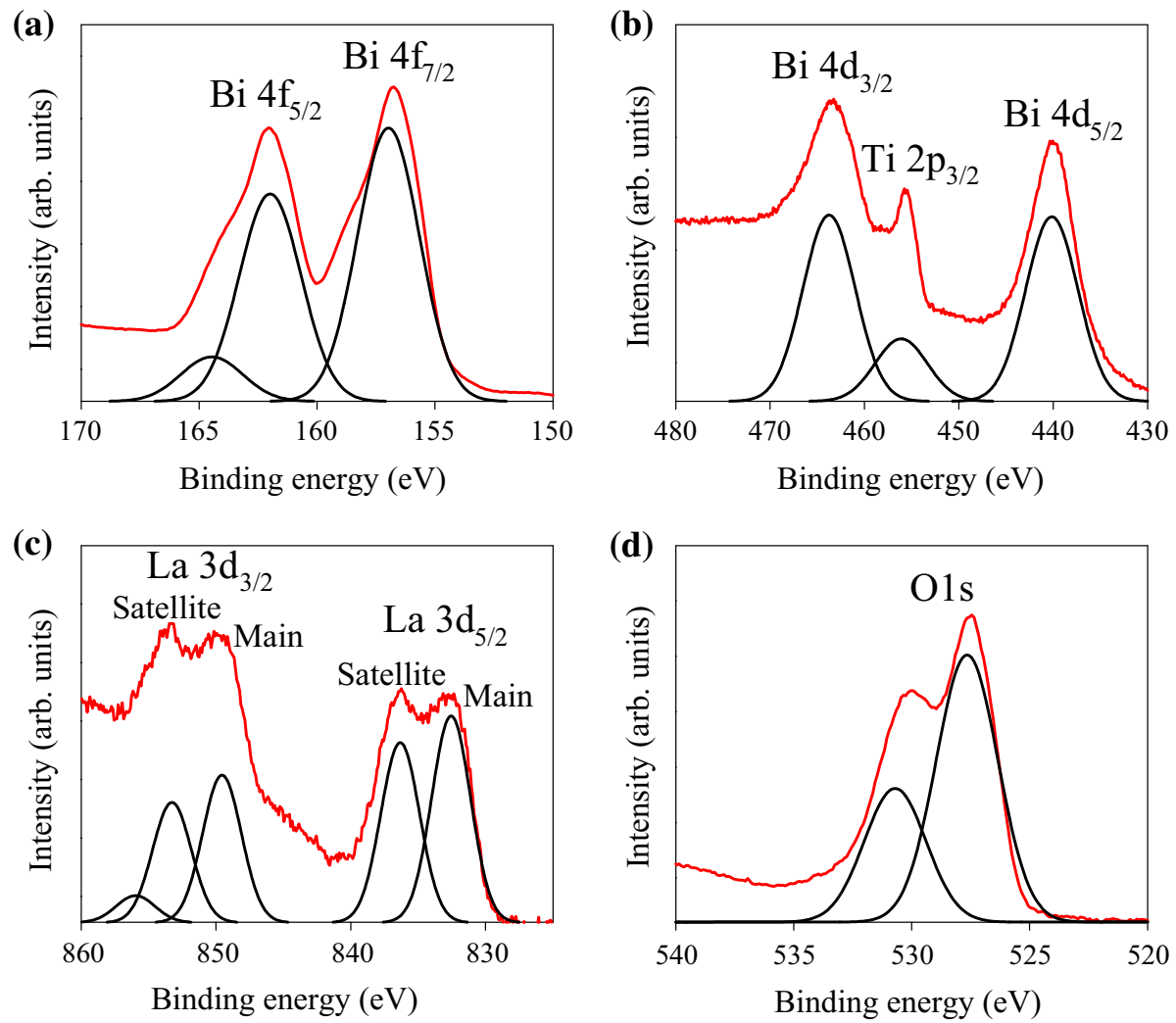

Figure 3. Core level photoemission of $\mathrm{Bi}_{3.00} \mathrm{La}_{1.00} \mathrm{Ti}_{3} \mathrm{O}_{12}$ : (a) $\mathrm{Bi} 4 \mathrm{f}$, (b) $\mathrm{Bi} 4 \mathrm{~d}$ and $\mathrm{Ti} 2 \mathrm{p}$, (c) La $3 \mathrm{~d}$ and (d) $\mathrm{O} 1 \mathrm{~s}$.

to the orange light emission. It was observed that the small area is associated with the violet and orange light emissions. The violet and orange emissions have minimum contribution in the PL spectrum.

On the other hand, the green light emission is predominant in the PL behaviour of $\mathrm{Bi}_{4} \mathrm{Ti}_{3} \mathrm{O}_{12}$. Deconvolution on $\mathrm{Bi}_{3.75} \mathrm{La}_{0.25} \mathrm{Ti}_{3} \mathrm{O}_{12}$ (figure $4 \mathrm{~b}$ ) affirms that the green light emission $(531 \mathrm{~nm})$ plays a major role in PL behaviour with small contribution from violet $(431 \mathrm{~nm})$ and orange emissions $(631 \mathrm{~nm})$. The maximum green emission $(538 \mathrm{~nm})$ is also mainly attributed to deconvolution on line shape of $\mathrm{Bi}_{3.00} \mathrm{La}_{1.00} \mathrm{Ti}_{3} \mathrm{O}_{12}$ as shown in figure 4c. It is worth noticing that the green emission is slightly shifted to a high wavelength with the increase in La content. Moreover, there is an additional peak above $700 \mathrm{~nm}$, which corresponds to infrared emission component. Figure $4 d$ shows the difference in visible emissions of $\mathrm{Bi}_{4} \mathrm{Ti}_{3} \mathrm{O}_{12}, \mathrm{Bi}_{3.75} \mathrm{La}_{0.25} \mathrm{Ti}_{3} \mathrm{O}_{12}$ and $\mathrm{Bi}_{3.00} \mathrm{La}_{1.00} \mathrm{Ti}_{3} \mathrm{O}_{12}$. The visible emission is generally referred to as a deep-level or trap-state emission, which is usually due to oxygen vacancies. Based on a report [14], the green emission is attributed to oxygen vacancies. It also notes that the green emission is associated with electron transition from the level of ionized oxygen vacancies to the valence band. It was reported that the increase of the emission intensity is mainly due to the increase in the number of oxygen vacancies [15].
On the basis of above reports, it clearly indicates that high oxygen vacancies are detected in $\mathrm{Bi}_{4} \mathrm{Ti}_{3} \mathrm{O}_{12}$ as compared with La-doped samples. As discussed in XPS analysis (figure 3), the oxygen vacancies were located in the vicinity of Bi ions. This finding shows that oxygen vacancies commonly exist in $\mathrm{Bi}_{4} \mathrm{Ti}_{3} \mathrm{O}_{12}$. However, it is interesting to note that the green emission intensity was abruptly decreased with La doping. This indicates that La doping suppresses the formation of oxygen vacancies by stabilizing the adjacent oxide ions. This also explains that the opportunity of electron transition from the energy level of oxygen vacancies to the valence band is decreased.

\subsection{Ferroelectric hysteresis loop measurements}

Figure 5 shows the ferroelectric hysteresis loops of $\mathrm{Bi}_{4} \mathrm{Ti}_{3} \mathrm{O}_{12}$ and La-doped samples, which were recorded at room temperature. The $P_{\mathrm{r}}$ values for $\mathrm{Bi}_{3.75} \mathrm{La}_{0.25} \mathrm{Ti}_{3} \mathrm{O}_{12}, \mathrm{Bi}_{3.50} \mathrm{La}_{0.50} \mathrm{Ti}_{3} \mathrm{O}_{12}$, $\mathrm{Bi}_{3.25} \mathrm{La}_{0.75} \mathrm{Ti}_{3} \mathrm{O}_{12}$ and $\mathrm{Bi}_{3.00} \mathrm{La}_{1.00} \mathrm{Ti}_{3} \mathrm{O}_{12}$ are 8.3, 9.4, 9.6 and $5.2 \mu \mathrm{C} \mathrm{cm}^{-2}$, respectively, while the $E_{\mathrm{c}}$ values are 39 , 40,35 and $18 \mathrm{kV} \mathrm{cm}^{-1}$, respectively. The $P_{\mathrm{r}}$ improved with $\mathrm{La}$ doping except for $\mathrm{Bi}_{3.00} \mathrm{La}_{1.00} \mathrm{Ti}_{3} \mathrm{O}_{12}$. The improved polarization with La doping from 0.25 to 0.75 can be explained by larger distortion of structure in those samples as compared with $\mathrm{Bi}_{4} \mathrm{Ti}_{3} \mathrm{O}_{12}$. In addition, the improved polarization can be also associated with the reduction in 

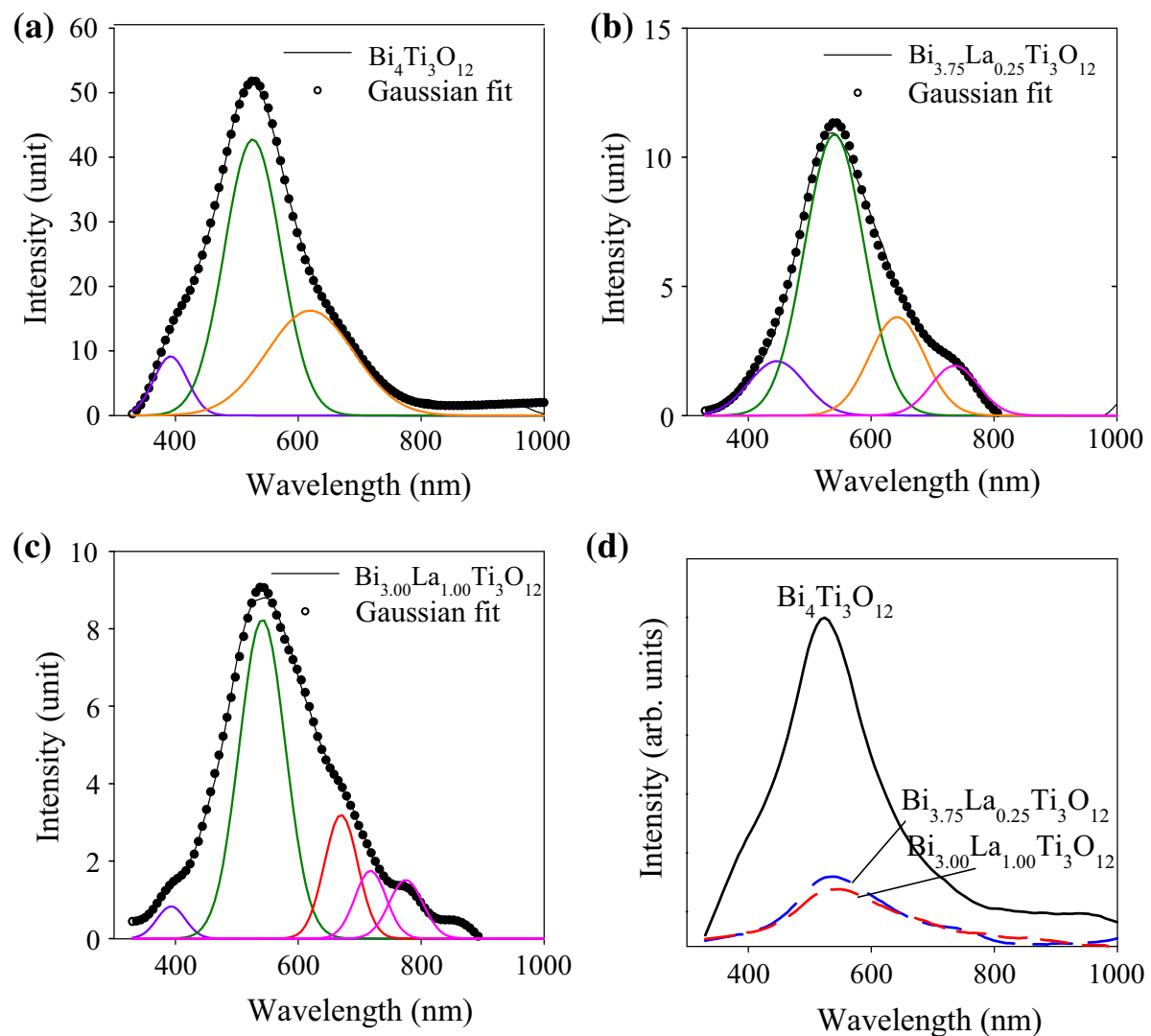

(d)

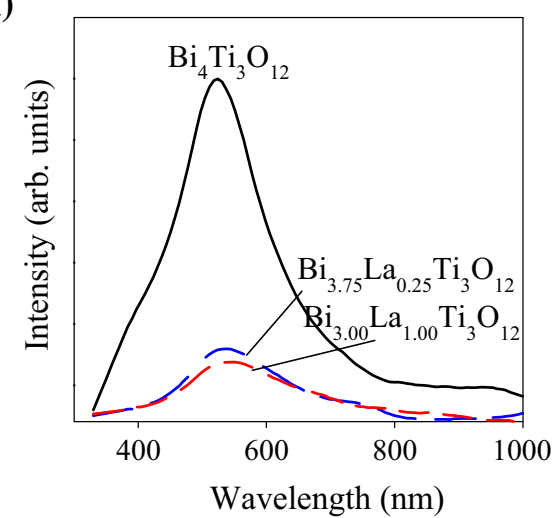

Figure 4. Deconvolution of the PL spectra of (a) $\mathrm{Bi}_{4} \mathrm{Ti}_{3} \mathrm{O}_{12}$, (b) $\mathrm{Bi}_{3.75} \mathrm{La}_{0.25} \mathrm{Ti}_{3} \mathrm{O}_{12}$, and (c) $\mathrm{Bi}_{3.00} \mathrm{La}_{1.00} \mathrm{Ti}_{3} \mathrm{O}_{12}$ and (d) comparison of PL spectra for respective samples.

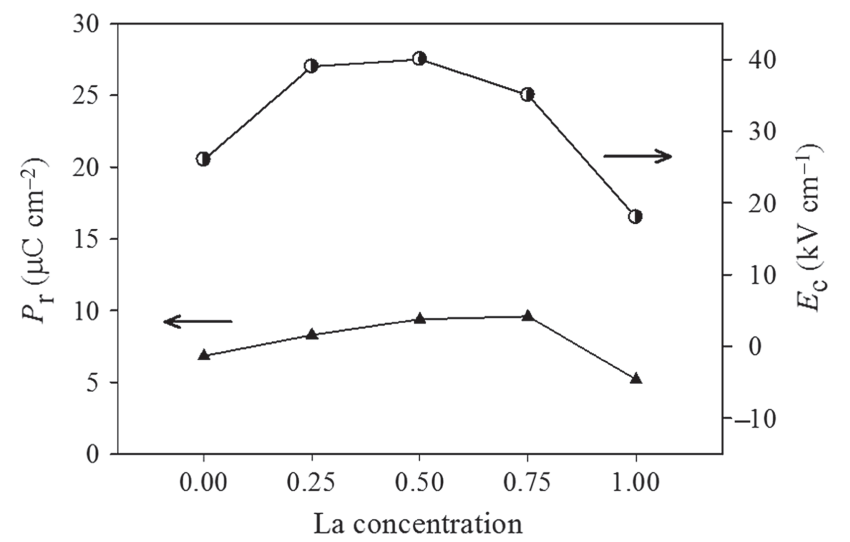

Figure 5. Ferroelectric hysteresis loops of $\mathrm{Bi}_{4} \mathrm{Ti}_{3} \mathrm{O}_{12}$ and La doping.

oxygen and bismuth vacancies due to La doping [16]. The exceptional trend of $\mathrm{Bi}_{3.00} \mathrm{La}_{1.00} \mathrm{Ti}_{3} \mathrm{O}_{12}$ is due to the low covalent interaction, which originates from the hybridization between $\mathrm{Ti} 3 \mathrm{~d}$ and $\mathrm{O} 2 \mathrm{p}$ electronic orbitals [17]. However, it was also noted that the $E_{\mathrm{c}}$ of $\mathrm{Bi}_{3.00} \mathrm{La}_{1.00} \mathrm{Ti}_{3} \mathrm{O}_{12}$ is lower by almost 2 times as compared with other La-doped samples. Such a low value of $E_{\mathrm{c}}\left(\mathrm{Bi}_{3.00} \mathrm{La}_{1.00} \mathrm{Ti}_{3} \mathrm{O}_{12}\right)$ is not well understood. Therefore, a detailed study on this will be recommended for future work. From the application viewpoint, lower $E_{\mathrm{c}}$ is better for non-volatile random access memory devices.

\section{Conclusion}

Investigations of $\mathrm{Bi}_{4} \mathrm{Ti}_{3} \mathrm{O}_{12}$ and $\mathrm{La}$ doping at different concentrations $(0.25,0.50,0.75$ and $1.0 \mathrm{~mol} \%)$ were successfully carried out. Several results shown by XRD, XPS and PL clearly indicate that the La doping is a feasible method to improve the structural stability of $\mathrm{Bi}_{4} \mathrm{Ti}_{3} \mathrm{O}_{12}$, which then resulted in better ferroelectric properties. This can be also explained by the fact that La doping suppresses the formation of oxygen vacancies by stabilizing the adjacent oxide ions.

\section{Acknowledgements}

Special thanks to Universiti Teknikal Malaysia Melaka (FRGS/1/2014/TK04/FTK/02/F00207) for financial support.

\section{References}

[1] Park B H, Kang B S, Bu S D, Noh T W, Lee J and Jo W 1999 Nature 401682

[2] Zhi-hui C, Jun-fu Q, Cheng L, Jian-ning D and Yuan-yuan Z 2010 Ceram. Int. 36241 
[3] Herrera Robles J O, Rodríguez González C A, De La Torre S D, Fuentes Cobas L E, García Casillas P E and Camacho Montes H 2012 J. Alloys Compd. 536511

[4] Xiang P-H, Kinemuchi Y, Nagaoka T and Watari K 2005 Mater. Lett. $\mathbf{5 9} 3590$

[5] Kim J S, Lee S Y, Lee H J, Ahn C W, Kim I W and Jang M S 2008 J. Electroceram. 21633

[6] Mao X Y, Mao F W and Chen X B 2006 Integr. Ferroelectr. 79155

[7] Chen M, Liu Z L, Wang Y, Wang C C, Yang X S and Yao K L 2004 Physica B Condens. Matter 35261

[8] Noguchi Y, Soga M, Takahashi M and Miyayama M 2005 Jpn. J. Appl. Phys. 446998

[9] Jovalekic C, Zdujic M and Atanasoska L 2009 J. Alloys Compd. 469441
[10] Hu Z, Gu H, Hu Y, Zou Y and Zhou D 2009 Mater. Chem. Phys. 11342

[11] Yang C, Fan H, Qiu S, Xi Y and Fu Y 2009 J. Non-Cryst. Solids 35533

[12] Zhang L, Lv P, Huang Z, Lin S, Chen D, Pan S et al 2008 Diamond Relat. Mater. 171922

[13] Rai A K, Singh N K, Lee S K, Mandal K, Kumar D and Parkash O 2011 J. Alloys Compd. 5098901

[14] Xian F and Li X 2013 Opt. Laser Technol. 45508

[15] Gu H, Hu Z, Hu Y, Yuan Y, You J and Zou W 2008 Colloids Surf. A 315294

[16] Simões A Z, Pianno R F, Riccardi C S, Cavalcante L S, Longo E and Varela J A 2008 J. Alloys Compd. 45466

[17] Guo D Y, Li M Y, Liu J, Fu L, Wang J, Yu B F et al 2007 Mater. Sci. Eng. B 142135 